Engineering Fracture Mechanics 77 (2010) 2550 - 2566

doi:10.1016/j.engfracmech.2010.06.002

\title{
Evaluating Stress Intensity Factors due to Weld Residual Stresses by the Weight Function and Finite Element Methods
}

\author{
Rui Bao ${ }^{1}$, Xiang Zhang ${ }^{2 *}$, Norvahida Ahmad Yahaya ${ }^{2}$ \\ ${ }^{1}$ Institute of Solid Mechanics, School of Aeronautic Science and Engineering, \\ Beihang University, Beijing, 100191, China \\ ${ }^{2}$ Department of Aerospace Engineering, School of Engineering, Cranfield University, \\ Bedford, MK43 0AL, U.K.
}

\begin{abstract}
This paper presents a study on the application of the weight function and finite element methods to evaluate residual stress intensity factors in welded test samples. Three specimen geometries and various residual stress profiles were studied. Comparisons of the two different methods were made in terms of the accuracy, easiness to use, conditions and limitations. Calculated residual stress intensity factors by the two different methods are in general in good agreement for all the configurations studied. Computational issues involved in executing these methods are discussed. Some practical issues are also addressed, e.g. treatment of incomplete or limited residual stress measurements, influence of transverse residual stresses, and modelling residual stress in short-length specimens. The finite element method is validated by well-established weight functions and thus can be applied to complex geometries following the procedures recommended in this paper.
\end{abstract}

Keywords: welded joints; residual stresses; stress intensity factor; finite element analysis; weight function.

\section{Nomenclature}

$a \quad$ half or full crack length in centre crack or edge crack geometry

$E, G \quad$ Young's modulus, Shear modulus

$E^{\prime} \quad$ effective Young's modulus, $E$ for plane stress or $E /\left(1-v^{2}\right)$ for plane strain

$h(a, x) \quad$ weight function

$K, K_{\mathrm{I}} \quad$ stress intensity factors (SIF), SIF for Mode I crack

$K_{a p p}, K_{\text {res }}, K_{\text {tot }} \quad$ SIF due to applied, residual and combined stress fields

$W \quad$ half width of plate with centre crack, width of plate with edge crack

$\kappa \quad \kappa=(3-v) /(1+v)$ for plane stress or $(3-4 v)$ for plane strain

$v \quad$ Poisson's ratio

\section{Introduction}

Since the adoption of modern welding techniques for manufacturing aerospace structures, evaluation of crack tip stress intensity factors (SIF) resulting from welding induced residual stresses has become an indispensable part to the damage tolerance analysis. This so-called residual stress intensity factor $\left(K_{\text {res }}\right)$ is required in the prediction of fatigue crack growth rates as well as in the residual strength calculations [1-6]. Current analysis methods are based on

\footnotetext{
Corresponding author. Tel.: +44 1234 754621; fax: +44 1234758203.

Email address: xiang.zhang@cranfield.ac.uk (X. Zhang)
} 
the superposition rule of linear elastic fracture mechanics (LEFM). One popular engineering method is to determine the effective stress intensity factor ratio $\left(R_{e f f}\right)$ to account for the residuals stress effect [1-2]. An alternative method is based on the crack closure concept originally proposed by Elber [7] by calculating the effective stress intensity factor range $\left(\Delta K_{\text {eff }}\right)$ in a combined stress field of the applied and residual. The validity of both methods has been generally accepted. Both $R_{\text {eff }}$ and $\Delta K_{\text {eff }}$ are determined by calculating the $K_{\text {res }}$ and using the superposition method [2-4, 8]. Therefore, the key task is to evaluate the $K_{\text {res }}$.

The weight function method (WFM) and the finite element method (FEM) have been widely employed for calculating SIFs. The former has been successfully used by many researchers for welded test samples [1,5,9]. Closed-form or approximate analytical solutions are available for calculating the $K_{\text {res }}$ and, in general, the solutions are exact or accurate enough. However, most weight functions were developed for simple geometries or require finite width correction. Some weight functions are in very complicated forms that the calculation process involves solving complex integral equations. On the other hand, the FEM is a more robust and versatile tool for complex geometries and loading conditions. It has been successfully used in the fracture analysis in welds $[3,10,11]$. This method is getting more popular owing to the rapid development of fast computers and implementation of fracture mechanics analysis routines in the commercial FE packages. The most important case is that welded structural components are usually in complex geometry for which FEM is more powerful than WFM in evaluating the effect of residual stresses on crack tip stress field. However, although the FEM is used in many studies of $K_{\text {res }}$ for many years and one recent study has shown good agreement with WFM calculated $K_{\text {res }}$ for the mid-crack tension geometry [11], the FEM delivered $K_{\text {res }}$ solutions are yet to be validated for further application to complex structural configurations and/or residual stress distributions. There are a few aspects that need to be explored to make sure the FE results are correct or acceptable.

The objectives of this paper are to validate the FEM by the well-established WFM for simple geometries and to establish good practices and procedures for application of FEM to complex welded structures. The available weight functions and their application in residual stress field are summarized firstly. Then, the procedure of evaluating $K_{r e s}$ via FEM is described. Discussion is made for the aspects of introducing residual stresses into FE model, dealing with incomplete measured residual stresses and effect of transverse residual stresses. The study cases include three specimen configurations and various residual stress profiles resulting from two welding processes and different crack positions. Comparisons of the two different methods are performed in terms of their accuracy, easiness for the users, and application scope and conditions. Computational issues and influential factors in these two methods are also discussed.

\section{Weight function method in residual stress field}

\subsection{The concept}

Two-dimensional plane stress or plane strain problems of a crack length $a$ in an infinite body subjected to an arbitrary symmetrical loading can be solved provided that certain results are known for one symmetrical loading, i.e. displacement of the crack faces, $v^{(1)}(a, x)$, and the stress intensity factor, $K_{\mathrm{I}}^{(1)}$ [12]. The SIF for any other symmetrical loading at the crack tip $x=a$ is given by

$$
K_{\mathrm{I}}=\int_{0}^{a} \sigma(x) h(a, x) \mathrm{d} x
$$

where $\sigma(x)$ is the stress over the crack site in an un-cracked body, $h(a, x)$ the weight function that is independent of $\sigma(x)$. 


$$
h(a, x)=\frac{8 G}{1+\kappa} \frac{1}{K_{\mathrm{I}}^{(1)}} \frac{\partial v^{(1)}}{\partial a}
$$

The Green's function is an earlier approach that is similar to the weight function method [13]. In order to apply the method, it is necessary to know the appropriate Green's function and the distribution of stress along the crack site in the un-cracked solid. Once these are known, the technique will give exact solutions. Often this may not be available and it is then necessary to make approximations [12]. For the case of a two-dimensional problem of a cracked sheet containing a crack of length $2 a$ subjected to localized forces $\pm P$ acting at points on the crack surface and normal to the crack faces, the SIF is calculated by:

$$
K_{\mathrm{I}}=\frac{P}{\sqrt{\pi a}}\left(\frac{a+x}{a-x}\right)^{\frac{1}{2}} \equiv \frac{P}{\sqrt{\pi a}} G(x)
$$

If a pressure, $p(x)$, acts normal to the crack faces, $-a \leq x \leq a$, then

$$
K_{\mathrm{I}}=\frac{1}{\sqrt{\pi a}} \int_{-a}^{a} p(x) G(x) \mathrm{d} x=\int_{-a}^{a} p(x) \frac{1}{\sqrt{\pi a}} G(x) \mathrm{d} x=\int_{-a}^{a} p(x) g(a, x) \mathrm{d} x
$$

The Green's function, $G(x)$, for this particular problem is:

$$
g(a, x)=\frac{1}{\sqrt{\pi a}} G(x)=\frac{1}{\sqrt{\pi a}} \sqrt{\frac{a+x}{a-x}}
$$

Eq. (4) is consentaneous to Eq. (1) in form.

In the following sections, both weight functions and Green's functions are expressed as $h(a, x)$, and the stresses acting on the crack-free body are expressed by $\sigma(x)$.

In order to apply the WFM to calculate the SIF resulting from weld thermal residual stresses, it is necessary to know $\sigma(x)$ and $h(a, x)$. The residual stress distributions, $\sigma(x)$, can be obtained by either experimental measurements [14-15], e.g. the diffraction methods, the hole drilling, and the cut-compliance method, or the inverse method from crack growth rate data [16], or via thermal stress analysis of welding process. The availability of $\sigma(x)$ is the prerequisite of both the WFM and FEM.

The WFM should give exact solution providing that the correct $h(a, x)$ is used. Many different weight functions of either closed-form or approximate are available for simple configurations, i.e. centre crack and edge $\operatorname{crack}(\mathrm{s})$ [17].

\subsection{Available weight functions for simple configurations}

Although the distributions of weld residual stresses always manifest different characteristics and profiles due to the different welding processes, from the numerical integration method point of view, load acting on the crack length interval $\Delta a$ can be treated as point load when $\Delta a$ is infinitesimal. So, all the weight functions, including the approximate forms, developed for the point load can be applied for calculating SIF due to distributed residual stress.

\section{1) Weight functions for an infinite sheet}

Green's function, Eq. (4) and (5), is the simplest form of weight function for an infinite with centre crack of length $2 a$, Fig. 1a, $[18,19]$. For edge crack in a semi-infinite sheet, Fig. 1b, Sih [20] used the approximate form of weight function expressed by Eq. (6).

$$
h(a, x)=\frac{1}{\sqrt{\pi a\left(1-(x / a)^{2}\right)}}\left[1.3-0.3(x / a)^{\frac{5}{4}}\right]
$$




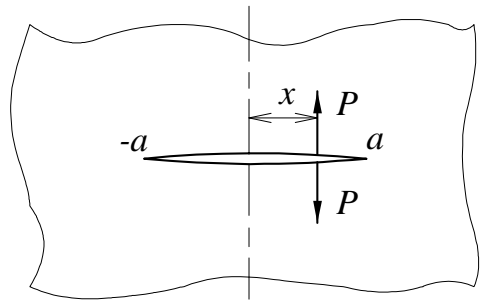

(a)

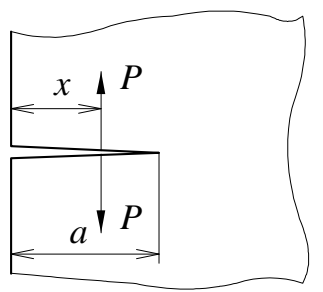

(b)

Fig. 1 Configurations of infinite sheet with centre (a) and edge crack (b).

\section{2) Weight functions for finite width sheet}

Several weight functions are developed for the simple configurations of finite width sheet with a centre or edge crack as shown in Fig. 2.

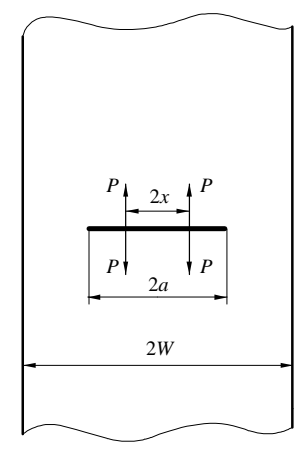

(a)

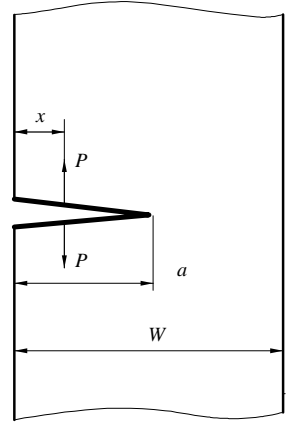

(c)

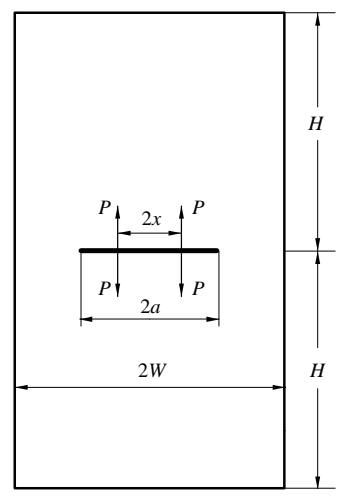

(b)

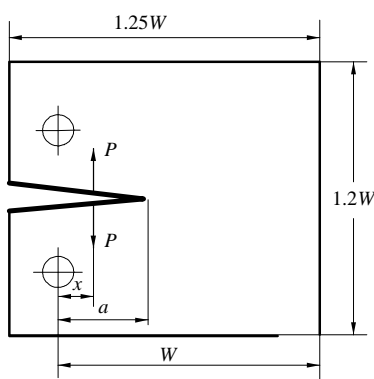

(d)

Fig. 2 Configuration of finite width sheet with a center or edge crack: (a) Infinite length center crack; (b) finite length center crack; (c) infinite length edge crack; (d) finite length edge crack

Tada et al. [19] developed a weight function expressed by Eq. (7) for finite width, infinite length sheet with centre crack subjected symmetrical point loads as shown in fig. 2a. Tada stated that this weight function should give better accuracy if $a / W<0.5$

$$
h(a, x)=\frac{2}{\sqrt{2 W}}\left\{1+0.297 \sqrt{1-\left(\frac{x}{a}\right)^{2}}\left[1-\cos \left(\frac{\pi a}{2 W}\right)\right]\right\} \sqrt{\tan \left(\frac{\pi a}{2 W}\right)}\left\{1-\left[\frac{\cos \left(\frac{\pi a}{2 W}\right)}{\cos \left(\frac{\pi x}{2 W}\right)}\right]^{2}\right\}^{-\frac{1}{2}}
$$


Wu and Carlsson [17] derived Eq. (8) for a centre crack in a finite rectangular plate, Fig. 2b. For the special cases of $H / W \geq 2.0$, Eq. (9) can be used to determine the simple expressions for the $\beta_{i}(a / W)$ functions (within $1 \%$ for the weight function for $a / W \leq 0.5$ ).

$$
\begin{gathered}
h(a, x)=\frac{1}{\sqrt{\pi a}} \sum_{i=1}^{3} \beta_{i}\left(\frac{a}{W}\right)\left[1-\left(\frac{x}{a}\right)^{2}\right]^{i-\frac{3}{2}} \\
\beta_{1}(a / W)=2.0 \\
\beta_{2}(a / W)=\frac{\pi a}{2 W} \tan \left(\frac{\pi a}{2 W}\right) \\
\beta_{3}(a / W)=0
\end{gathered}
$$

The weight functions for infinite sheet, i.e. Green's function in Eq. (5) and Sih's function in Eq. (6), etc., can also be applied to finite width when multiplying a correction function, such as the Isida's finite width correction function [21].

A weight function for single edge crack in a finite width but infinite length sheet, Fig. 2c, was firstly developed by Bueckner [22], Eq. (10).

$$
h(a, x)=\frac{2}{\sqrt{2 \pi(a-x)}}\left[1+m_{1}\left(\frac{a-x}{a}\right)+m_{2}\left(\frac{a-x}{a}\right)^{2}\right]
$$

where

$$
\begin{aligned}
& m_{1}=0.6147+17.1844\left(\frac{a}{W}\right)^{2}+8.7822\left(\frac{a}{W}\right)^{6} \\
& m_{2}=0.2502+3.2889\left(\frac{a}{W}\right)^{2}+70.0444\left(\frac{a}{W}\right)^{6}
\end{aligned}
$$

Kaya and Erdogan [23] also presented a weight function for such geometry, Eq. (12), where $g_{i}(a / W), i=1,2,3,4$, can be found in [23] and are listed in the Appendix of this paper.

$$
h(a, x)=\frac{2}{\sqrt{\pi a}} \frac{g_{1}\left(\frac{a}{W}\right)+g_{2}\left(\frac{a}{W}\right) \frac{x}{a}+g_{3}\left(\frac{a}{W}\right)\left(\frac{x}{a}\right)^{2}+g_{4}\left(\frac{a}{W}\right)\left(\frac{x}{a}\right)^{3}}{\left(1-\frac{a}{W}\right)^{\frac{3}{2}} \sqrt{1-\left(\frac{x}{a}\right)^{2}}}
$$

$\mathrm{Wu}$ and Carlsson also presented a weight function for this configuration in [17],

$$
h(a, x)=\frac{1}{\sqrt{2 \pi a}} \sum_{i=1}^{5} \beta_{i}\left(\frac{a}{W}\right)\left[1-\left(\frac{x}{a}\right)\right]^{i-\frac{3}{2}}
$$

where $\beta_{i}(a / W)$ is much more complicated than that in Eq. (8)-(9), and can be expressed by several equations [17]. For simplification in application, $\mathrm{Wu}$ and Carlsson provided some discrete values of $\beta_{i}(a / W)$ for selected non-dimensional crack lengths which are listed in the Appendix A, Table A1.

If the edge crack is in a plate of finite width and length as shown Fig. 2d, e.g. the compact tension, $\mathrm{C}(\mathrm{T})$, then the effect of sample's length on the SIF must be taken into account by choosing a suitable weight function.

Fett and Munz [24] developed a weight function for the C(T) geometry, Eq. (14), by using the fundamental principle of Petroski and Achenbach [25]. 


$$
h(a, x)=\sqrt{\frac{2}{\pi a}} \frac{1}{\sqrt{1-\frac{x}{a}}}\left[1+\sum_{v}^{\mu} \frac{A_{v, \mu}\left(\frac{a}{W}\right)^{\mu}}{\left(1-\frac{a}{W}\right)^{\frac{3}{2}}}\left(1-\frac{x}{a}\right)^{v+1}\right]
$$

where, $A_{v, \mu}$ are the weight function coefficients and listed in the Appendix A, Table A2. $\mathrm{Wu}$ and Carlsson [17] also proposed a weight function for the $\mathrm{C}(\mathrm{T})$ geometry, Eq. (15).

$$
h(a, x)=\frac{1}{\sqrt{2 \pi a}} \sum_{i=1}^{4} \beta_{i}\left(\frac{a}{W}\right)\left[1-\left(\frac{x}{a}\right)\right]^{i-\frac{3}{2}}
$$

where $\beta_{i}(a / W)$ are different from those in Eq. (8) and Eq. (13). The discrete values of $\beta_{i}(a / W)$ for selected non-dimensional crack lengths are listed in the Appendix A, Table A3.

\section{3) Other weight functions}

Beghini and Bertini [26,27] developed weight functions for inclined cracks at sharp Vnotches and semi-plane. Weight function for a 3D surface crack is also available [28]. For other configurations, such as a centre crack in a circular disc, double edge crack, multiple cracks, etc., corresponding weight functions have been developed by Tada [19], Wu [17], Fett and Munz [24] et al. Weight functions of general forms were also proposed by Fett et al. [29], and Sha and Yang [30].

\subsection{Evaluating SIF due to welding residual stresses by WFM}

\subsubsection{Available SIF solutions}

Various kinds of weight functions have been applied to determine the intensity of the crack tip elastic field for cracks introduced into the residual stress field (including thermal stresses). In the absence of external loads, residual stressed are self-balanced, built-in field, which require no special treatment when using the WFM. The method is based on the superposition principle [19].

There are some closed-form SIF solutions that are deduced by the WFM. Tada et al. [31] presented SIF solutions for various crack-absent residual stress distributions and crack geometries. For example, they used the Green's function to obtain the SIF solution for centre crack in infinite width plate. When the residual stress distribution is expressed by Eq. (16), Fig. 3a, $K_{\mathrm{I}}$ is given by Eq. (17).

$$
\begin{gathered}
\sigma(x)=\sigma_{0} \cdot e^{-\frac{1}{2}\left(\frac{x}{c}\right)^{2}}\left[1-\left(\frac{x}{c}\right)^{2}\right] \\
K_{r e s}=\sigma_{0} \sqrt{\pi a} e^{-0.42\left(\frac{a}{c}\right)^{2}}\left[1-\frac{1}{\pi}\left(\frac{a}{c}\right)^{2}\right]
\end{gathered}
$$

For a finite width rectangular plate, $\mathrm{Wu}$ and Carlsson [17] presented the SIF solution according to this stress distribution using their weight function, Eq. (8). Tada's and Wu's solutions are compared in Fig. 3b, which shows that: (1) The SIF results given by Tada and $\mathrm{Wu}$ agree with each other very well when the width of the plate is adequate compared with the distribution of residual stress. (2) For inadequate width ratio, e.g. $W / c=4$, although the 
stress at the edge is almost zero, the width effect could not be ignored; weight functions with width correction gives more accurate result in this case.

However, weld residual stresses as measured are not always in the single peak form as Fig. 3a and Eq. (16) describe. Most cases need numerical integration of Eq. (1). This will be demonstrated through practical examples in Section 4.

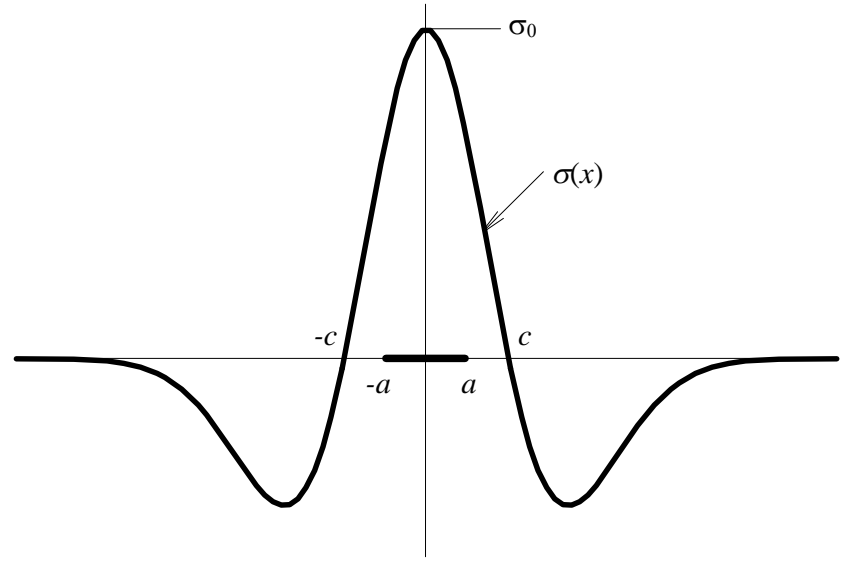

(a)

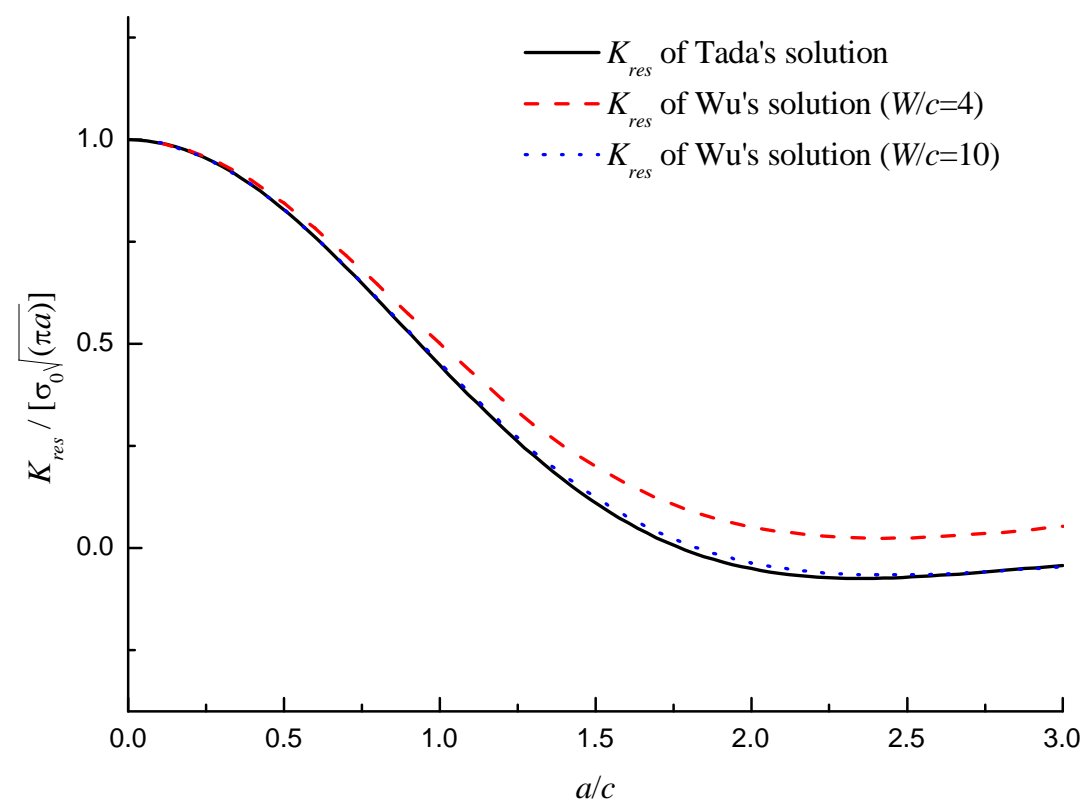

(b)

Fig. 3 WF solution of SIF given for a given residual stress field; (a) residual stress distribution; (b) comparison of Tada's and Wu's solutions

\subsubsection{Influence of incomplete residual stress measurement data}

Residual stresses should be self-balanced in the absence of external loads. However, during residual stress measurement experiments tensile residual stresses often attract more attention than compressive stresses. Consequently measured stress distribution is often incomplete and dominated by tensile stresses resulting in un-balanced stress field. If the equilibrium condition is not fulfilled, evaluated SIF distribution as a whole is in general meaningless. However, in some cases of engineering failure assessment, attention is on crack propagation in the weld zone. Thus, if the values of $K_{\text {res }}$ are correct in region of interest, then the assessment is 
meaningful. The purpose of the work presented in this section is to understand the effect of incomplete RS on $K_{r e s}$ if measured residual stresses are available only in the crack growth region.

Two cases are studied: case 1 is centre crack with a longitudinal weld in the middle of plate, Fig. 4a; case 2 is edge crack with longitudinal weld, Fig. 4b. For demonstration purpose, the analytical stress distribution in Eq. (16) is used and plotted in Fig. 4; solid and dotted lines form a full and balanced stress field. Assumed un-balanced residual stress is achieved by limiting $\sigma(x)$ to region $-1.1 c \leq x \leq 1.1 c$ (solid line); stresses outside this region (dotted line) are set to zero. For simplicity and emphasising on the effect of un-balanced stress, effect of sample length is not considered. Wu and Carlsson weight function, Eq. (8), is used for case 1, and Bueckner's weight function, Eq. (10), is used for case 2. Normalized SIF values for case 1 and 2 are shown in Figs. 5a and 5b, respectively, and compared with those SIF solutions due to balanced stresses. It indicates that: (1) For the centre crack that has the same symmetric axis as the stress distribution, the imbalance of the stresses has no influence on $K_{\text {res }}$ while the crack length $a$ is within the boundary of the region where the residual stresses are known. (2) For the edge crack, the result obtained from un-balanced stresses is totally different from that gained by balanced stresses. Therefore, for the edge crack geometry full and balanced residual stress field is necessary for evaluating residual SIF by WFM. In other words, if a crack is completely embedded in the region where the residual stress is evaluated or correctly interpolated and the crack and the residual stress distribution have the same symmetric axis, (e.g. the centre crack case), then partial knowledge of the stress is not a problem when using the WFM. The required function $\sigma(x)$ is enough for obtaining the correct $K_{r e s}$, and the stresses in other regions do not affect the result. However, the problem of partial knowledge of residual stresses arises when the WFM is applied to a crack for which residual stress is known only on a portion of the crack length (e.g. an edge crack). In this case application of the WFM needs the residual stress to be reasonably extrapolated on the whole crack domain and the equilibrium condition has to be correctly fulfilled.

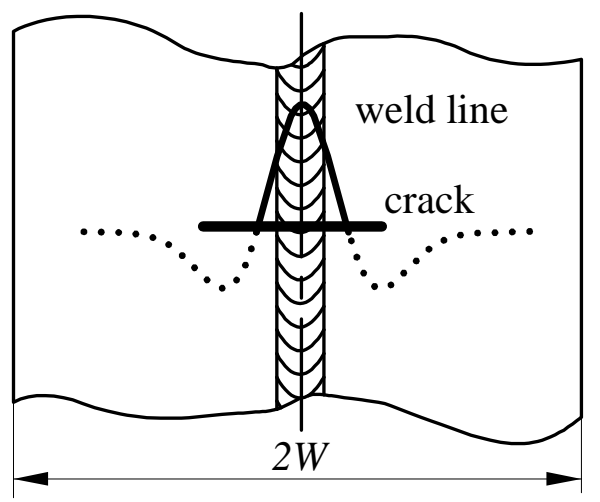

(a)

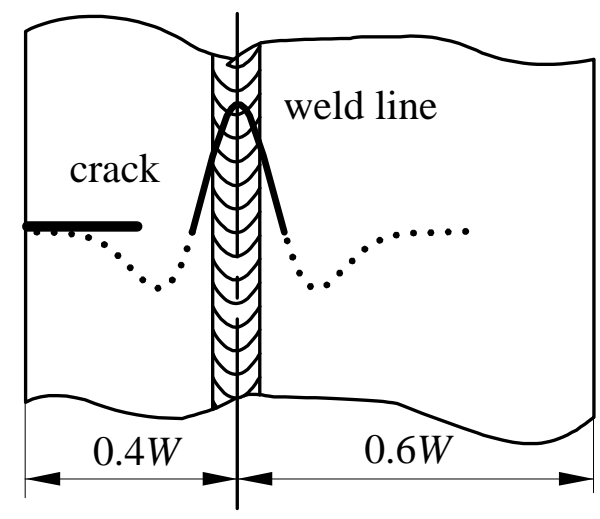

(b)

Fig. 4 Balanced and incomplete residual stresses $(W=10 c)$ in (a) centre crack and (b) edge crack samples 


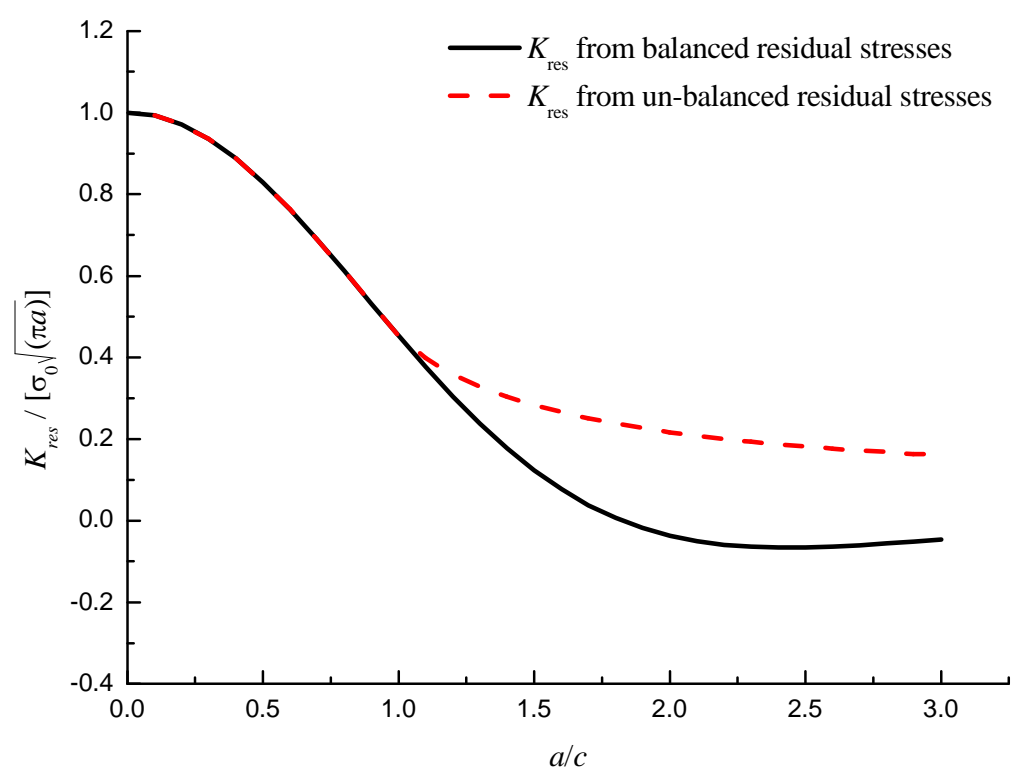

(a)

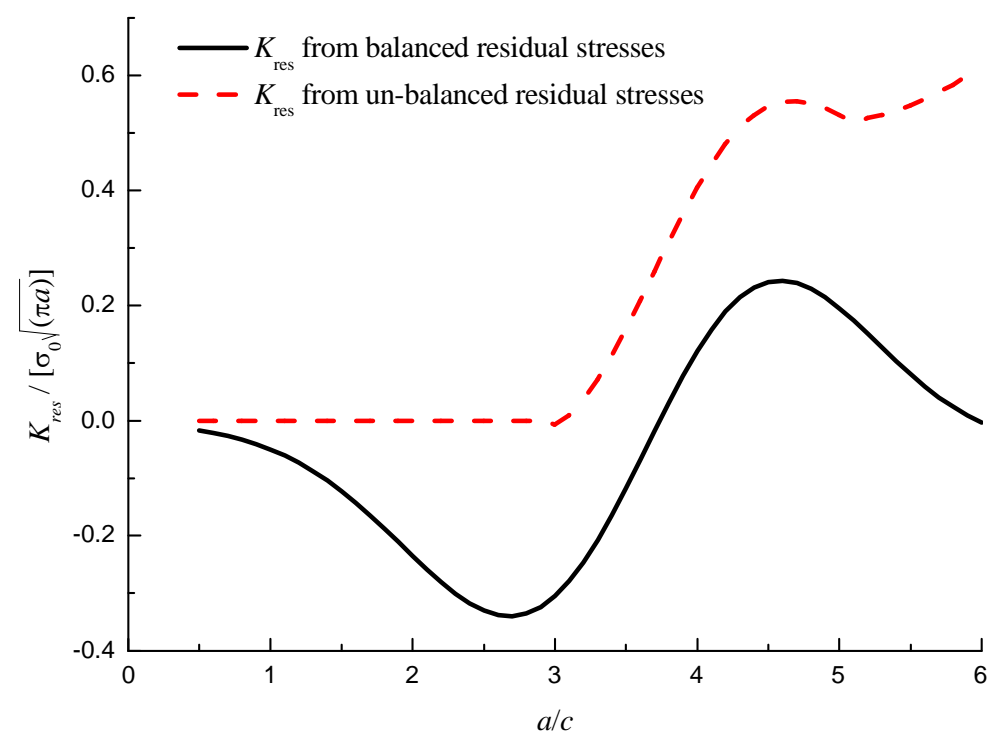

(b)

Fig.5 Influence of incomplete residual stress on SIF: (a) centre crack; (b) edge crack.

\section{Finite element method}

\subsection{Introduction of residual stresses into FE models}

For evaluating $K_{\text {res }}$, it is important to input correct initial stress conditions to numerical models to characterise measured residual stresses. The function of defining initial stress condition is available in many commercial FE software packages, e.g. ABAQUS subroutine SIGINI [32], ANSYS command INISTATE [33]. These initial stresses should be equilibrated in the first analysis step to result in zero stresses in model's free edges and self-equilibrium condition without any constraint. ABAQUS command "UN-BALANCED STRESSES" can be called to do this, while in ANSYS, the initial stress must be applied in the first load step and be equilibrated automatically. 
According to the experimental measurements, the profiles of weld residual stresses are almost identical along the $y$-axis that is parallel to the weld line. Therefore, elements with the same $x$ coordinate should have the same initial stress condition. In other words, if the residual stress distribution is expressed by discrete value $\sigma_{i}$ at $x_{i},(i=1,2, \cdots, n)$, initial stress $\left(\sigma_{i-1}+\sigma_{i}\right) / 2$ should be introduced to all the elements located within $\left(x_{i-1}, x_{i}\right)$.

To obtain correct $K_{\text {res }}$ value, it is necessary to make sure that the resulted stress distribution in the FE model after the equilibrium is in accordance with the measured residual stress field within an acceptable discrepancy. However, it is not always possible to obtain the same output stress field as the input residual stress. For configurations of relatively short length with respect to the width, such as the $\mathrm{C}(\mathrm{T})$ geometry, obtained residual stresses are found to be much lower than inputted values after the equilibrium step. This issue was also mentioned in [34].

An example is given here to demonstrate the influence of specimen length. The residual stress distribution follows eq. (16), letting $c=10 \mathrm{~mm}$, and is introduced to the FE model with discrete values over every $1 \mathrm{~mm}$ distance. Case 1 has the average residual stress $\left(\sigma_{i-1}+\sigma_{i}\right) / 2$ introduced to all the elements located within $\left(x_{i-1}, x_{i}\right)$, whereas in case 2 residual stresses are only inputted into the elements within $y<10 \mathrm{~mm}$ (to model a short-length specimen). After the self-equilibrium balance, the resultant residual stresses being kept in the FE model of the case 2 is much lower than the actual input values as shown in Fig. 6.

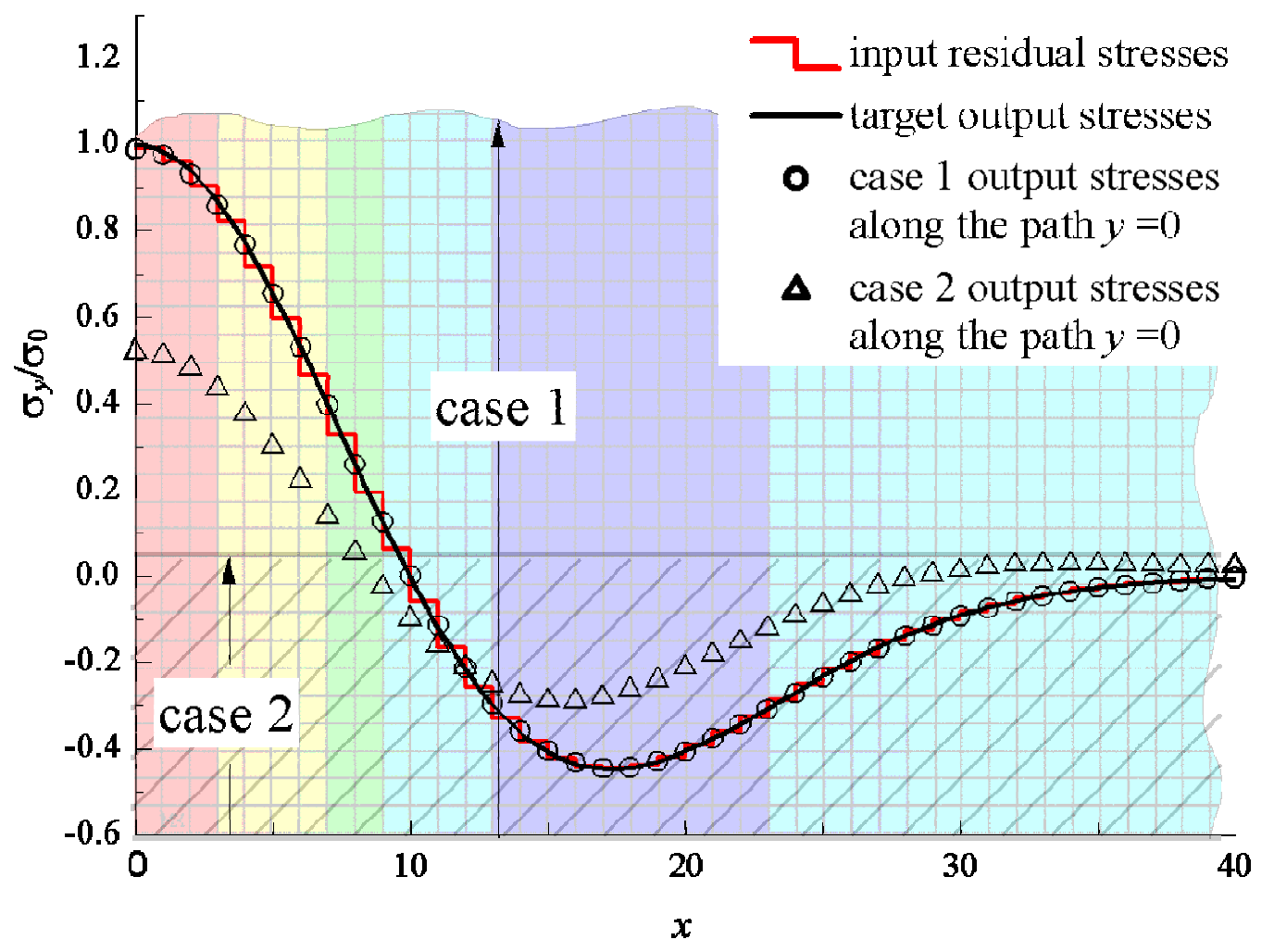

Fig. 6 Input and output of initial stresses

Therefore, when dealing with the $\mathrm{C}(\mathrm{T})$ configuration, the input initial stresses should be increased so that the actual residual stresses in the FE model, after the self-equilibrium step, can match the measured values. In [34], the proportional integral (PI) adjustment, which is widely used in the area of automatic control, was applied to introduce residual stresses into FE models. It is a good way to solve this problem. The adjustment equation is: 


$$
\sigma(x)_{\text {input }}^{j+1}=\sigma(x)_{\text {input }}^{j}+\beta\left(\sigma(x)_{\text {target }}-\sigma(x)_{\text {output }}^{j}\right)
$$

The procedure starts with the adjustment step $j=0$ and $\sigma(x)_{\text {input }}=\sigma(x)_{\text {target }}$, and ends when the agreement between $\sigma(x)_{\text {output }}$ and $\sigma(x)_{\text {target }}$ is satisfied, where $\sigma(x)_{\text {target }}$ is the measured residual stress distribution.

Welding process also introduces transverse residual stresses. Although, the magnitude of transverse residual stress is usually much smaller than that of the longitudinal residual stress, introducing transverse residual stress to FE model will affect the magnitude of the longitudinal residual stress after the equilibrium step; consequently, evaluated $K_{\text {res }}$ value will be affected. Therefore, it is important to check the output value of the longitudinal residual stress in the FE model to make sure that the residual stresses are introduced correctly.

\subsection{Calculating $K_{\text {res }}$ by FEM}

There are a few methods for evaluating the SIF by FEM, such as the crack tip displacements extrapolation, the $J$-integral, the strain energy approach, e.g. the virtual crack extension technique. The displacement extrapolation and $J$-integral methods are widely used practices and implemented in commercial FE software packages. However, the $J$-integral is no longer path-independent in the presence of thermal strains, path dependent plastic strains, body forces within the integration area, and pressure on the crack surface. Therefore, $J$-integral method is not suitable for evaluating SIF due to weld thermal residual stresses. For linear elastic analysis, the displacement extrapolation method is a good choice, which is simple and straightforward to obtain the SIF values based on FE results.

According to the LEFM, the crack tip displacement field in the load direction for a 2D problem is [35]:

$$
u_{y}=\frac{K_{\mathrm{I}}}{2 G} \sqrt{\frac{r}{2 \pi}} \sin \left(\frac{\theta}{2}\right)\left[\kappa+1-2 \cos ^{2}\left(\frac{\theta}{2}\right)\right]-\frac{K_{\mathrm{II}}}{2 G} \sqrt{\frac{r}{2 \pi}} \cos \left(\frac{\theta}{2}\right)\left[\kappa-1-2 \sin ^{2}\left(\frac{\theta}{2}\right)\right]
$$

where, $u_{y}, r, \theta$ are defined in crack tip coordinate, Fig. 7.

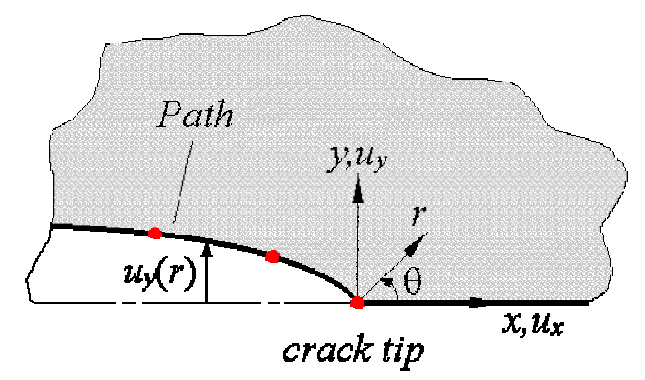

Fig. 7 Coordinate at crack tip and path for displacement extrapolation

The SIFs can be calculated from the FE solution according to the displacement extrapolation procedure [34] using Eq. (20).

$$
K_{\mathrm{I}}=\sqrt{2 \pi} \frac{2 G}{\kappa+1} \frac{\Delta u_{y}}{\sqrt{r}}
$$

where, $\Delta u_{y}$ is the displacement between the corresponding nodes located on the upper and lower crack surfaces, $r$ is the node coordinate. Away from the crack tip, $\Delta u_{y} / \sqrt{r}$ can be fitted by a linear function of $r$ : 


$$
\begin{aligned}
& \frac{\Delta u_{y}}{\sqrt{r}}=A+B \cdot r \\
& \lim _{r \rightarrow 0} \frac{\Delta u_{y}}{\sqrt{r}}=A
\end{aligned}
$$

Thus,

$$
K_{\mathrm{I}}=\sqrt{2 \pi} \frac{2 G A}{1+\kappa}
$$

The displacement extrapolation needs not to be done manually; the procedure is now implemented in some commercial FE packages and can be executed by calling a corresponding command. For example, in the ANSYS code, the "KCALC" command can be called in the general postprocessor after defining the path. When executing this command, care should be taken to define either the plane stress or plane strain state for a $2 \mathrm{D}$ problem. It is recommended to use a refined mesh in the region around the crack tip to capture the rapidly varying stress and deformation fields. The singularity elements at the crack tip mesh will result in more accurate SIF for linear elastic problems. However, the embedded procedure in ANSYS soft package uses the absolute value of the displacement when evaluating SIF via the "KCALC" command, the SIF values calculated by ANSYS will always be positive or zero. If the SIF is evaluated by the energy approach (e.g. the $J$-integral), then the value will also be positive or zero. While the influence of residual stresses on the SIF can be either positive or negative as shown in Fig. 5, i.e. $K_{\text {res }}$, which reflects the influence of residual stresses on crack tip stress field, $K_{\text {res }}$ is no longer a strict SIF that cannot be negative. To avoid modelling a nonlinear contact problem, we have used the following method. For negative residual stresses, both residual stress and external tension stress are applied to the FE model simultaneously to keep the crack completely open, i.e. $\Delta u_{y}>0$ at any position of the crack face. $K_{r e s}$ is then evaluated based on the superposition principle [35], Eq. (24).

$$
K_{r e s}=K_{t o t}-K_{a p p}
$$

\subsection{Influence of incomplete residual stresses on $\boldsymbol{K}_{\text {res }}$}

As mentioned in section 2.3, measured residual stresses are usually incomplete and tension dominated, which will result in inaccurate SIF when using the WFM. The same problem exists for using the FEM to evaluate $K_{\text {res }}$. Attempts have been made to balance the initial stresses artificially when inputting them to the FE models. A equilibrium-based least-squares smoothing method was proposed in [36] to obtain full-field residual stress using a set of residual stress data acquired by neutron diffraction over a limited region. Extensive FE calculations are required when using this method. To facilitate simple engineering calculations, two simple cases of artificially balanced stresses are studied in the present paper to demonstrate their influences on the $K_{\text {res }}$. The two geometries used in Section 2.3 and shown in Fig. 4 are used, and set $W=100 \mathrm{~mm}, c=10 \mathrm{~mm}, \sigma_{0}=1 \mathrm{MPa}$. The $K_{\text {res }}$ results from four different initial stresses cases are evaluated. Case 1 is the full-field balanced initial stress $\sigma(x)$ expressed by Eq. (16). Case 2 is the un-balanced case with incomplete $\sigma(x)$ located within $-1.1 c \leq x \leq 1.1 c$. These two cases are the same as those discussed in Section 2.3 for the WFM and shown in Fig. 4. Case 3 and Case 4 are two artificially balanced initial stress distributions shown in Fig. 8 (artificial balancing stresses are plotted by dashed lines). Incomplete initial stresses are balanced by either concentrated compressive stresses in case 3 
or distributed stresses in case 4. Calculated $K_{\text {res }}$ values are compared in Fig. 9. It can be said that: (1) For the region where the initial residual stress is known, calculated $K_{\text {res }}$ from unbalanced residual stress (case 2) is lower than the $K_{\text {res }}$ values calculated from balanced stresses. (2) The artificially balanced initial stress fields give acceptable $K_{\text {res }}$ values in the region where initial residual stress is known. (3) For the area where the initial residual stress is unknown, the authentic $K_{\text {res }}$ cannot be obtained.

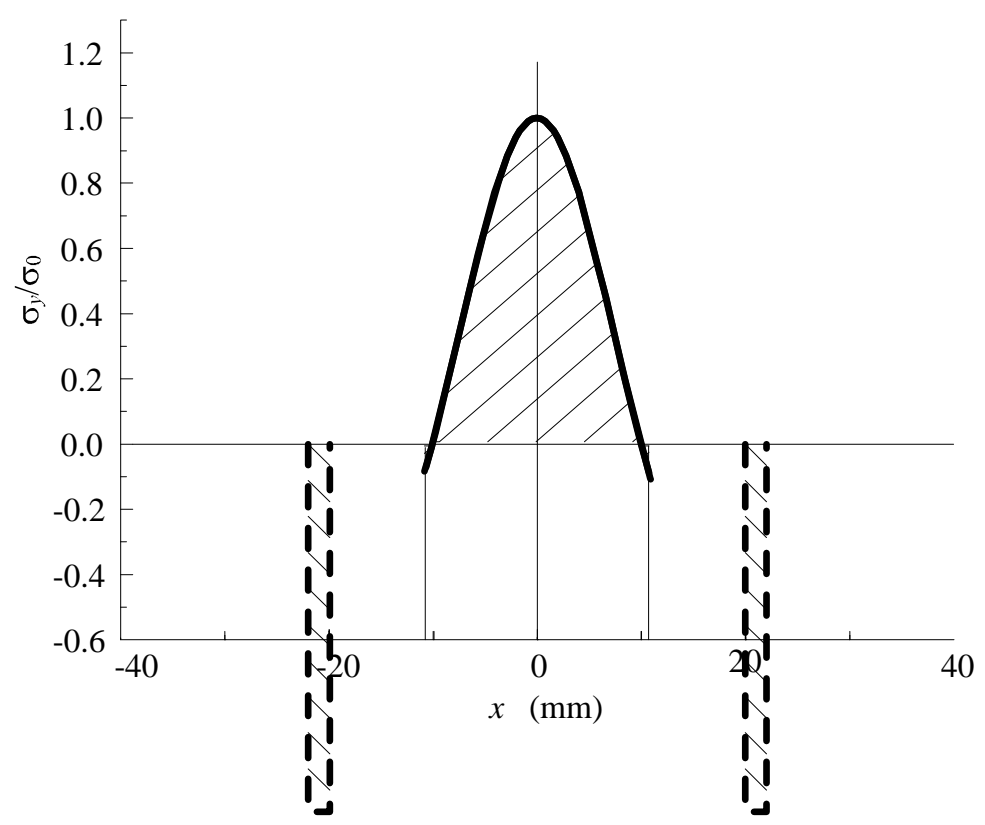

(a)

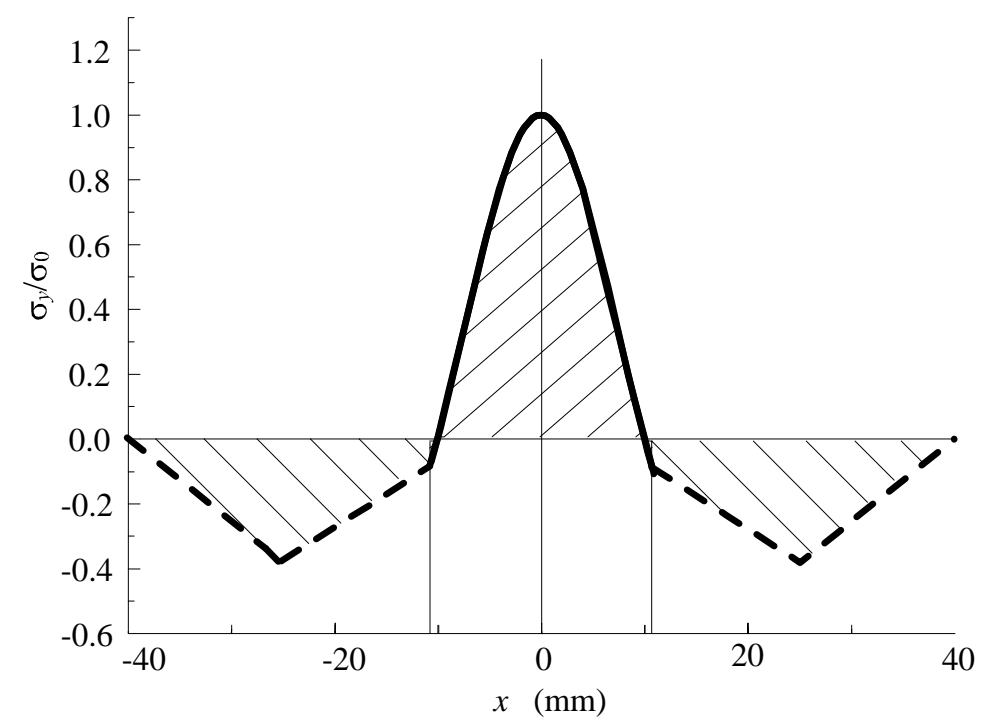

(b)

Fig. 8 Artificially balanced residual stresses: (a) with concentrated stress (case 3); (b) with distributed stress (case 4). 


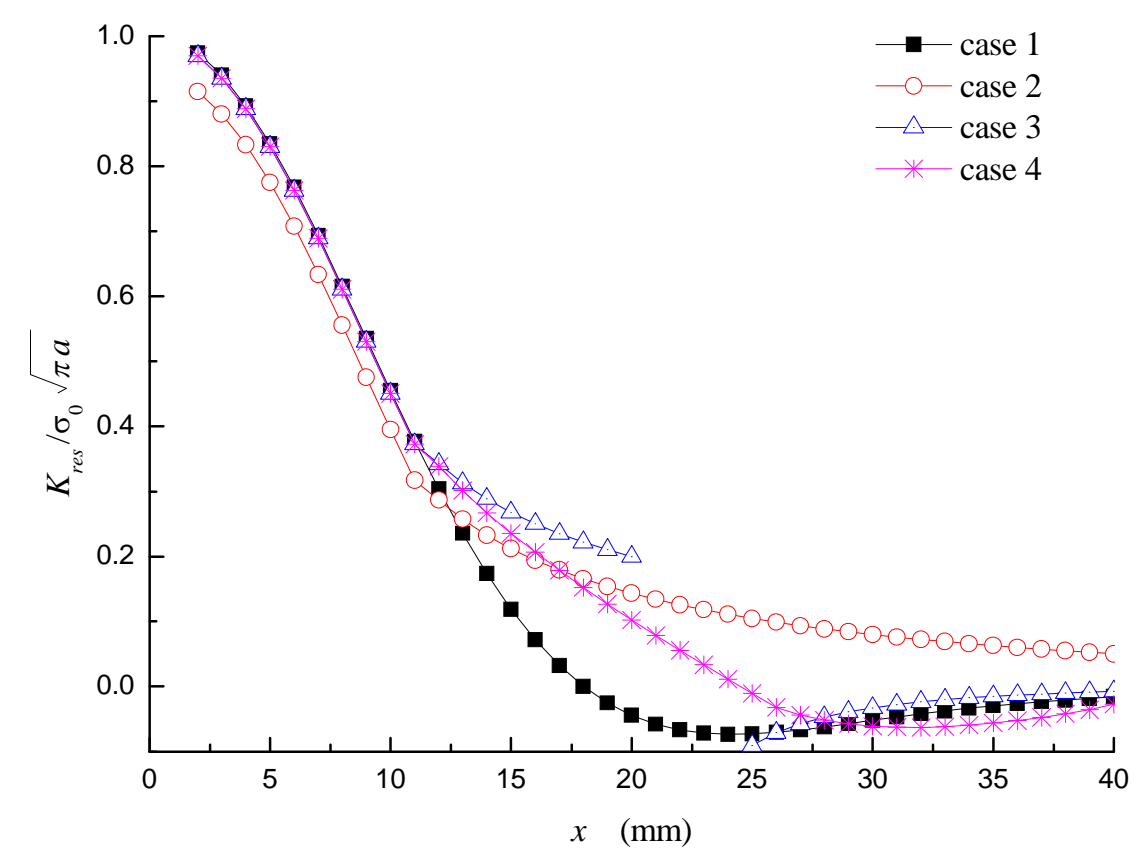

(a)

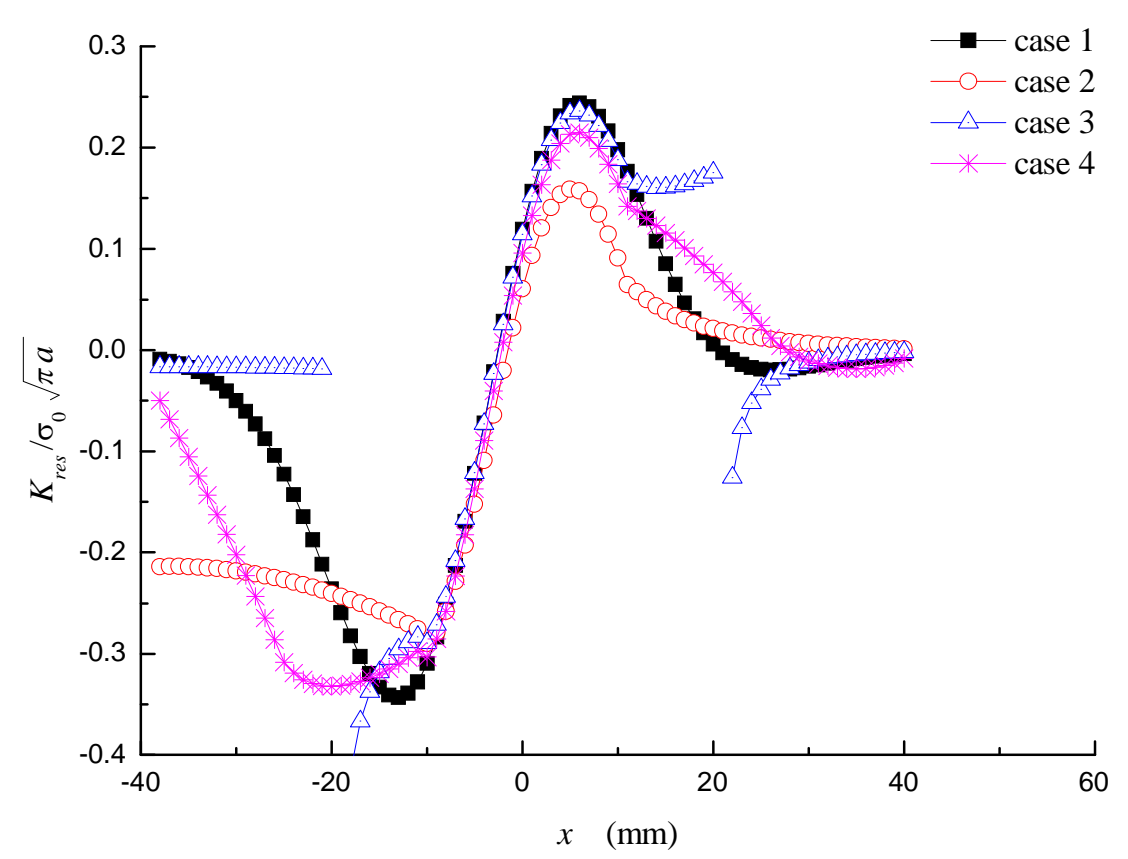

(b)

Fig. 9 FE results of $K_{\text {res }}$ for cases of different residual stress: (a) centre crack; (b) edge crack.

The FE results for the cases 1 and 2 are also compared with the WFM results and shown in Fig. 10. For the area where residual stress is known, it indicates that: (1) For centre crack configuration, the WFM calculated $K_{\text {res }}$ for the un-balanced residual stress field is exactly the same as that obtained by the self-balanced initial stress, whereas, the FEM results is 5.8\% lower. (2) For the edge crack configuration, the WFM overestimates the $K_{\text {res }}$, whereas, the FEM underestimates the $K_{\text {res }}$ if the initial residual stress is un-balanced. 


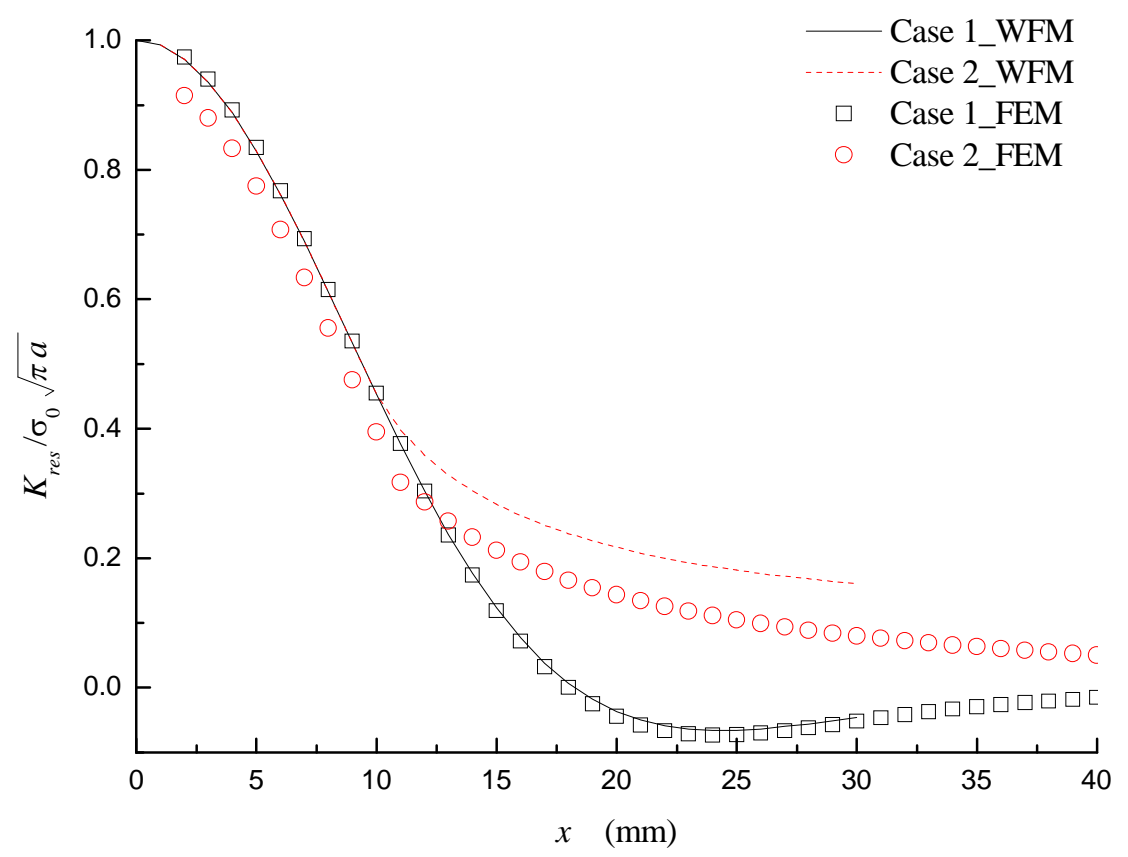

(a)

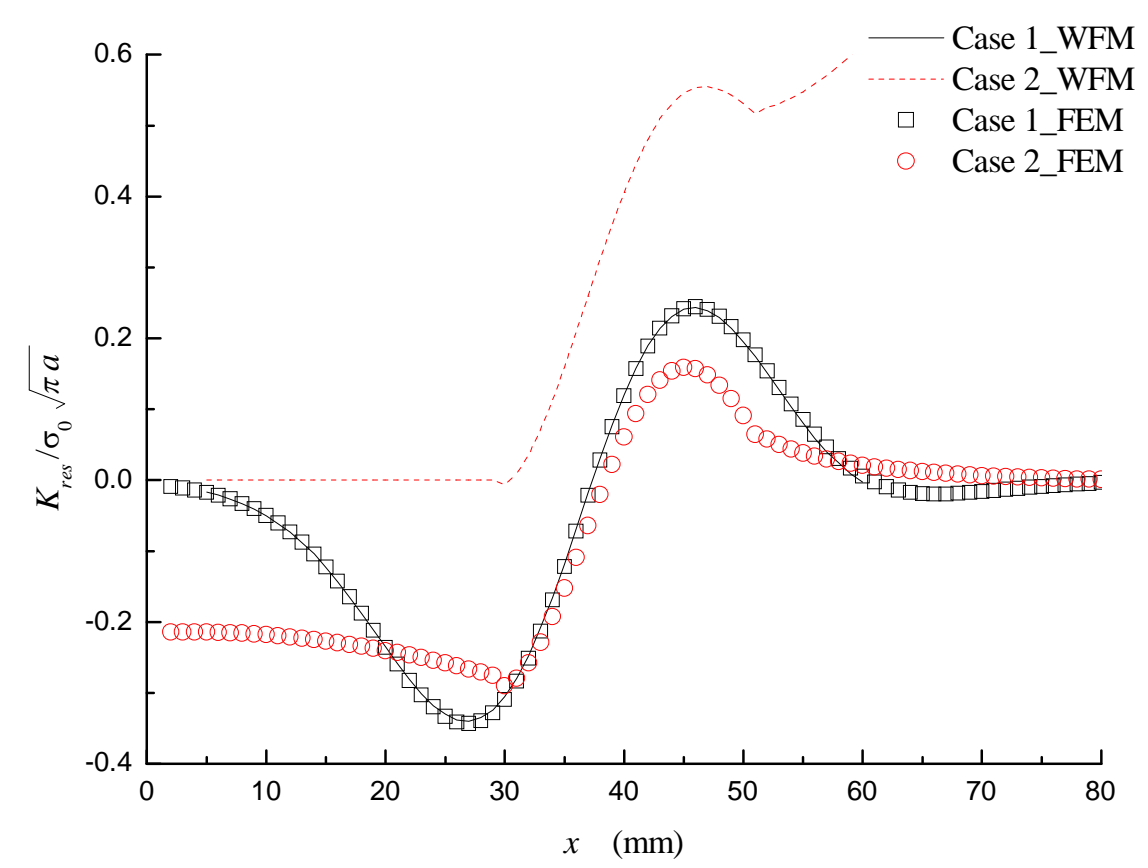

(b)

Fig.10 Comparison of FE and WF results for balanced (case 1) and unbalanced (case 2) residual stresses: (a) center crack, (b) edge crack.

\section{Case studies - comparison of WFM and FEM}

\subsection{VPPA welded AA $2024 \mathrm{M}(\mathrm{T})$ specimen}

The Variable Polarity Plasma Arc (VPPA) welding technology has been widely used in the aerospace industry. Residual stress distributions usually show multiple peaks. VPPA welded $\mathrm{M}(\mathrm{T})$ and $\mathrm{C}(\mathrm{T})$ configurations have been studied by Liljedahl et al [37] in terms of residual stress measurement and crack growth prediction. These two test sample geometries and 
measured residual stresses are used in this study to compare the FEM with the WFM. Test samples dimensions are shown in Fig. 11. A measured residual stress distribution for the $\mathrm{M}(\mathrm{T})$ configuration was presented in [37] and shown here in Fig. 12a. The residual stress distribution is considered to be symmetric, so it is averaged and mirrored before calculating the $K_{r e s}$. For the WFM analysis, residual stress plot was firstly fitted by a multi-peak function, eq. (25). For the FEM analysis, residual stress profile was artificially balanced (see the dotted lines in Fig. 12a).

$$
y(x)=y_{0}+\sum_{i=1}^{n} \frac{A_{i}}{W_{i} \sqrt{\pi / 2}} e^{-2 \frac{\left(x-X C_{i}\right)^{2}}{W_{i}^{2}}}
$$

where $A_{i}, \quad W_{i}$, and $X C_{i}$ are fitting parameters, $n$ is the number of peaks.

The $K_{\text {res }}$ results obtained by the Wu and Carlsson weight function, eq. (8), and the FEA are compared in Fig. 12b. It can be seen from Fig. 12b that the WFM and FEM results agree very well to each other when $a<24 \mathrm{~mm}(a / W<0.6)$. Since the error of $\mathrm{Wu}$ and Carlsson weight function is said to be less than $1 \%$ when $a / W \leq 0.5$ [17], when the crack length is much longer $(a / W>0.6)$, FEM gives more accurate evaluation.

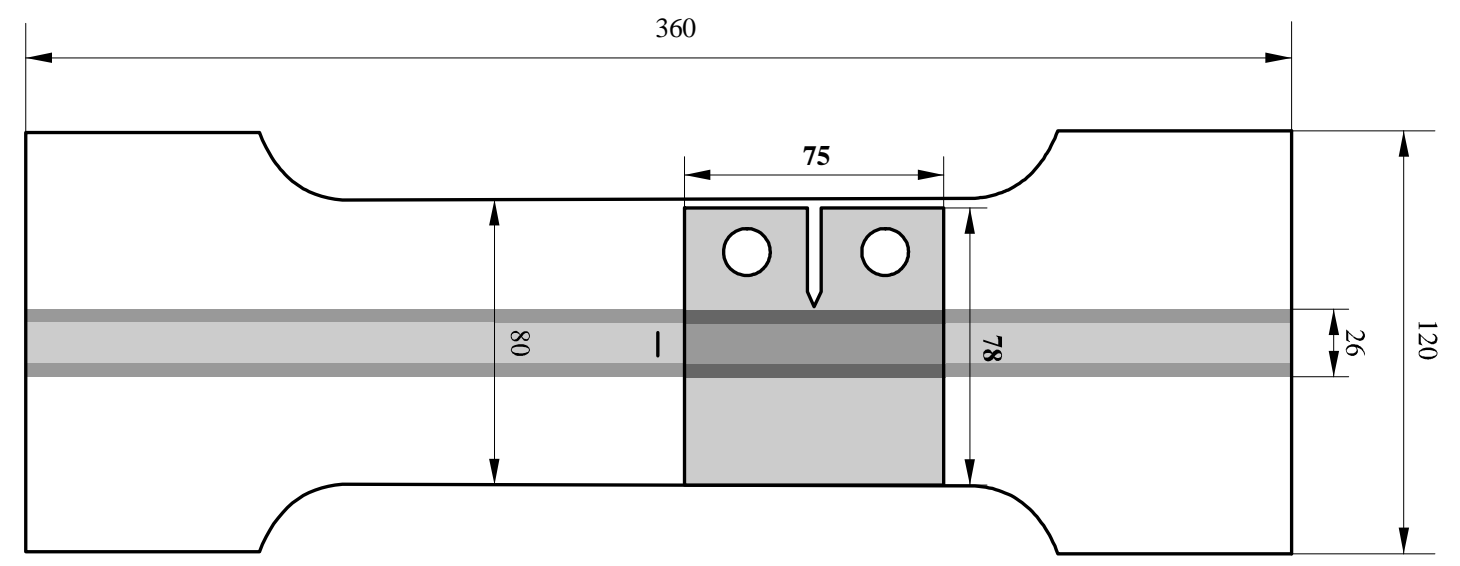

Fig. $11 \mathrm{M}(\mathrm{T})$ and $\mathrm{C}(\mathrm{T})$ specimens with a longitudinal VPPA weld; $\mathrm{C}(\mathrm{T})$ is cut form an $\mathrm{M}(\mathrm{T})$ specimen [37]; unit: $\mathrm{mm}$.

\subsection{VPPA welded AA 2024 C(T) specimen}

For the $\mathrm{C}(\mathrm{T})$ geometry, Fig. 11, measured residual stress distribution is taken from [37] and shown here in Fig. 13a. Since the C(T) was cut off from the $M(T)$ specimen, the original residual stress distribution should be the same as the $\mathrm{M}(\mathrm{T})$. However, cutting has resulted in stress redistribution and the measured residual stress field in the $\mathrm{C}(\mathrm{T})$ specimen is hence asymmetric and compressive at the weld centre contrary to the stresses in the $\mathrm{M}(\mathrm{T})$.

The redistribution of residual stress can be evaluated by FE analysis, which is in good agreement with the measured profile and values. The residual stress distribution introduced to the FE model should be the one before the cutting induced redistribution, i.e. the same as the $\mathrm{M}(\mathrm{T})$ and then introduce the notch and let the FE to release the stresses for the $\mathrm{C}(\mathrm{T})$. For the WFM, the residual stress should be the one without the notch (crack-free stresses). The $K_{\text {res }}$ results obtained by the Fett and Munz weight function, Eq. (14), and FE calculation for this geometry are compared in Fig. 13b. Notch tip is at $x=-10 \mathrm{~mm}$. The WFM and FEM results agree with each other very well. The difference at the beginning (notch tip) is due to the asymmetric geometry of the CT. The difference in the final part is due to the inherent limitation of the weight function for longer crack lengths. 


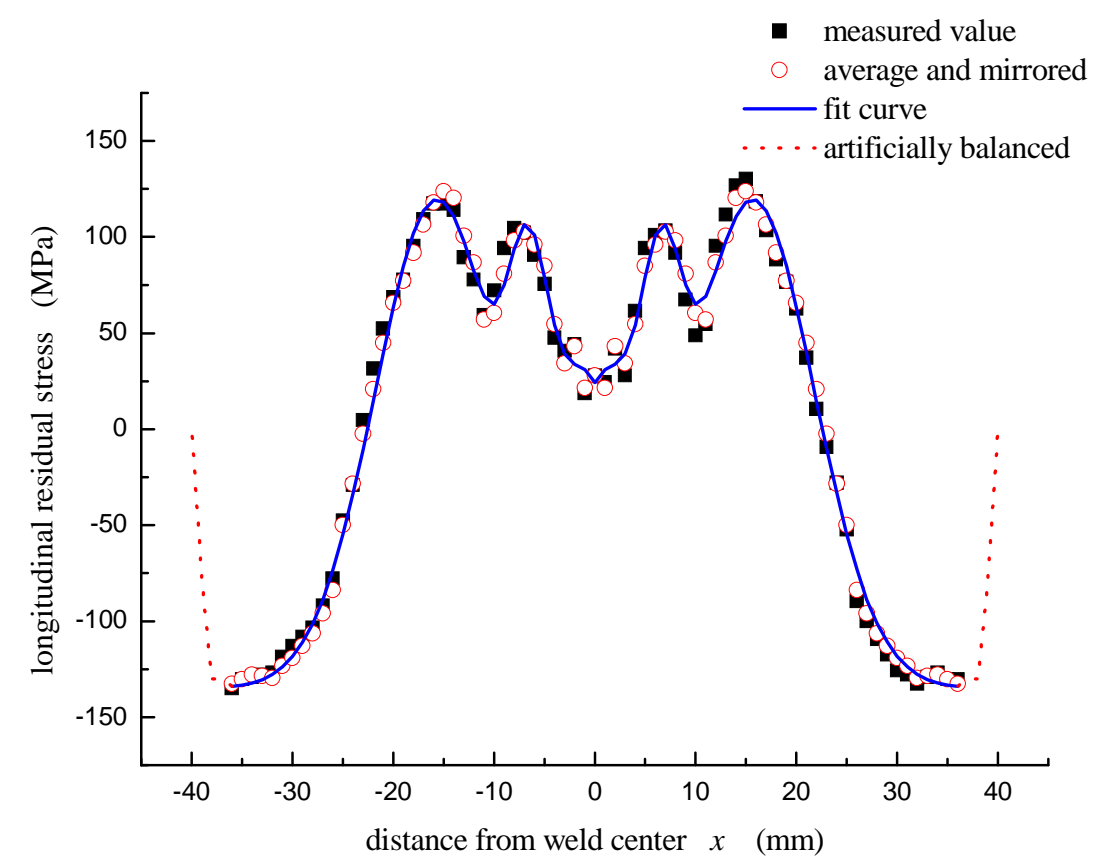

(a)

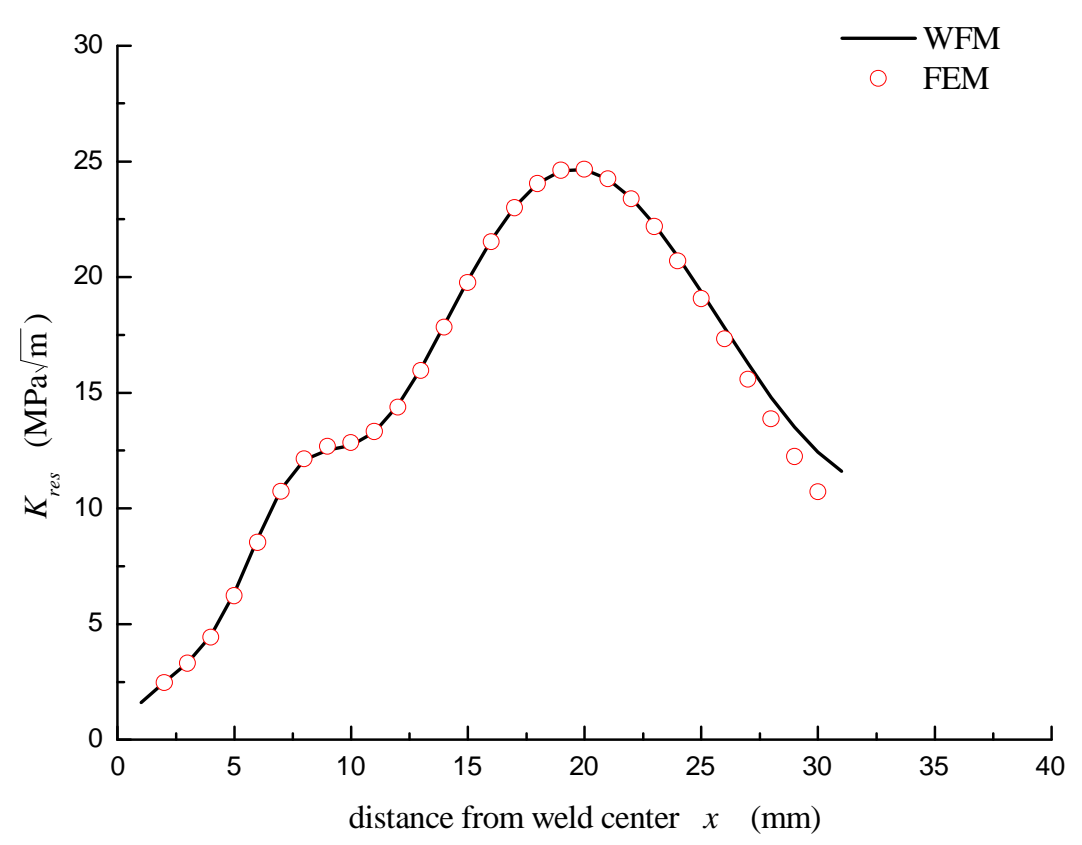

(b)

Fig. 12 (a) Longitudinal residual stress distributions; (b) calculated $K_{\text {res }}$ in the VPPA welded $2024 \mathrm{M}(\mathrm{T})$ sample.

\subsection{FSW welded AA 2195 ESE(T) specimen}

Friction Stir Welding (FSW) is an innovative solid-state welding technique developed for the aerospace applications. Residual stress distribution in the FS welds usually has the character of double peaks. Measured residual stress distribution for eccentrically-loaded single edge crack under tension, ESE(T), geometry was presented in [8], from which the specimen configuration and measured longitudinal residual stress distribution are taken for this study 
and shown in Fig. 14 and Fig. 15a. Residual stress measurement was conducted after cutting the notch, which results in the asymmetric stress profile. Since the initial stress for both the WFM and FEM should be the one without the notch, measured residual stress was mirrored from right to left and fitted by a multi-peak function with five peaks. Calculated $K_{\text {res }}$ by the Bueckner's weight function, eq. (10), and FE result are compared in Fig. 15b. It can be seen that the WFM and FEM results agree with each other when $a / W<0.6$.

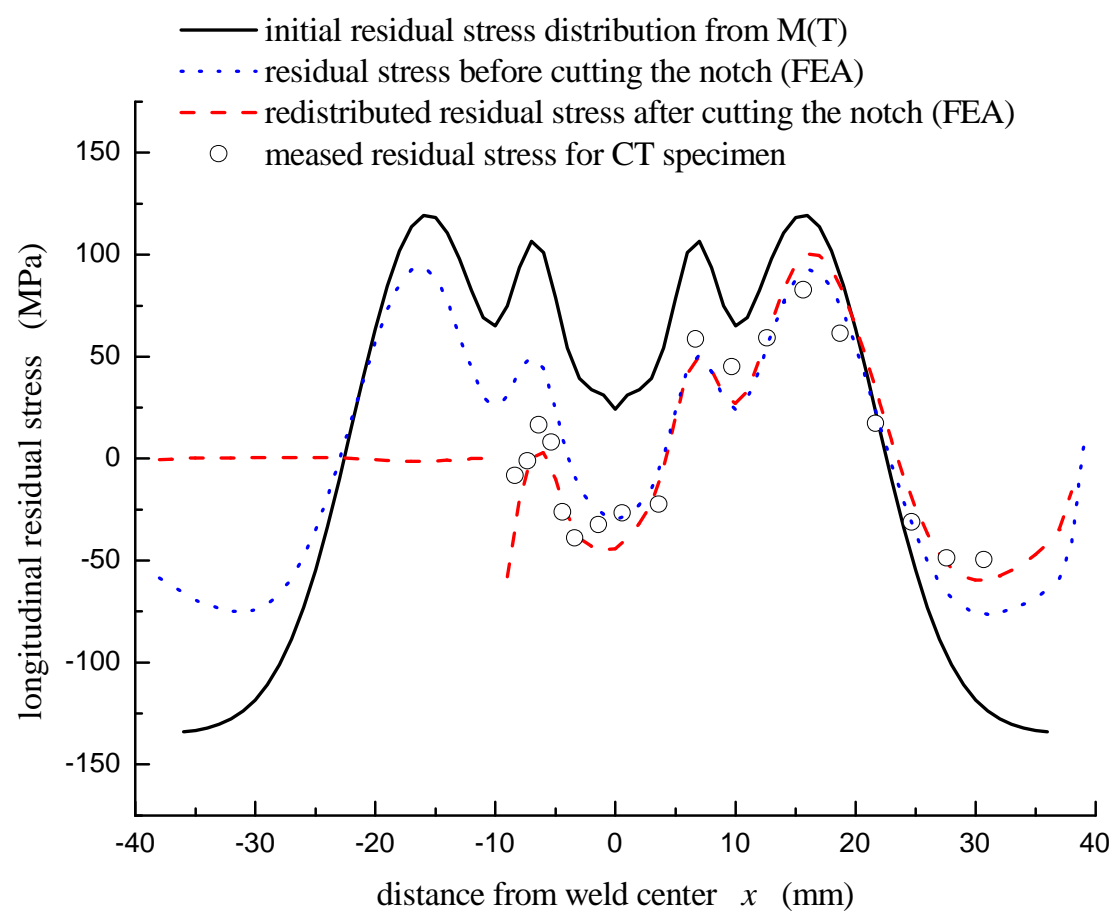

(a)

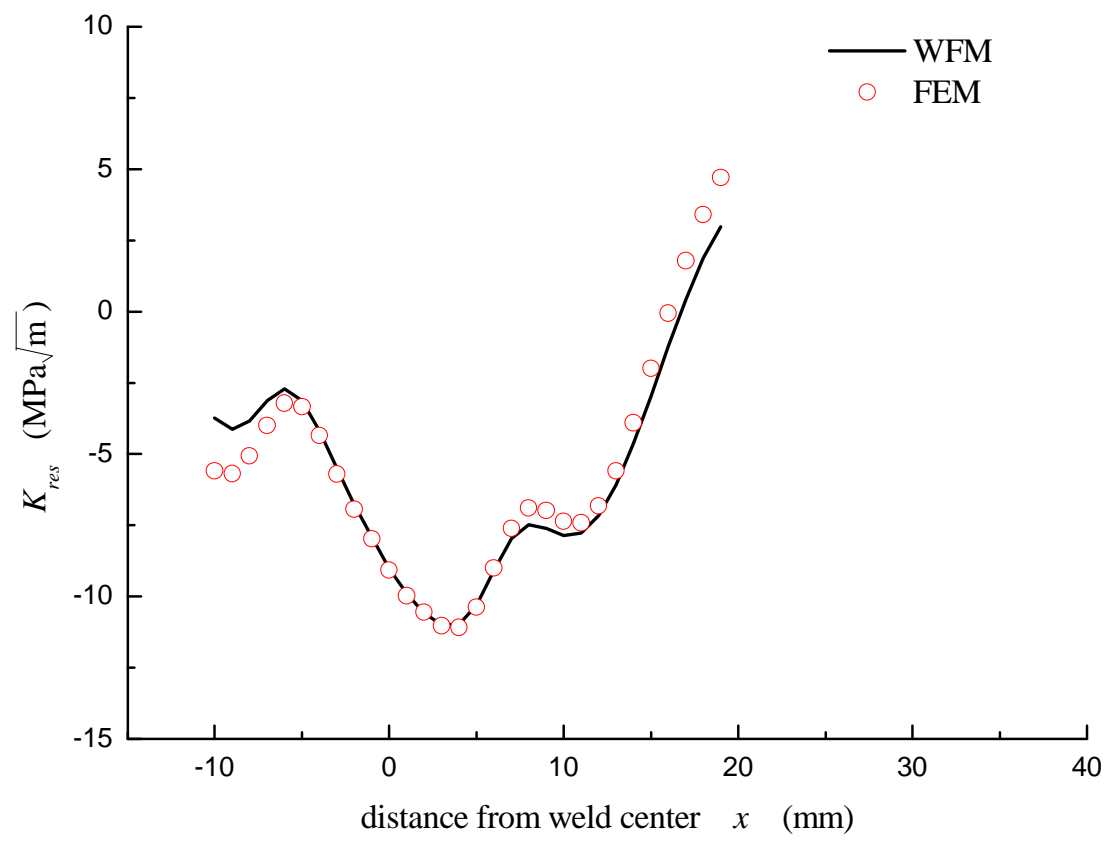

(b)

Fig. 13 (a) Residual stress redistribution in the C(T); (b) calculated $K_{\text {res }}$ for the VPPA 2024 $\mathrm{C}(\mathrm{T})$ specimen 


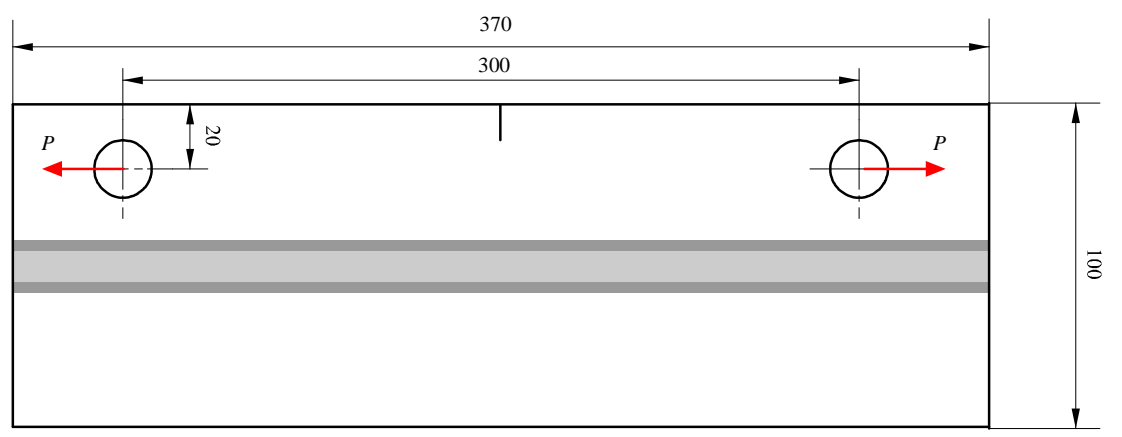

Fig. 14 ESE(T) specimen with longitudinal FSW line; unit: mm.

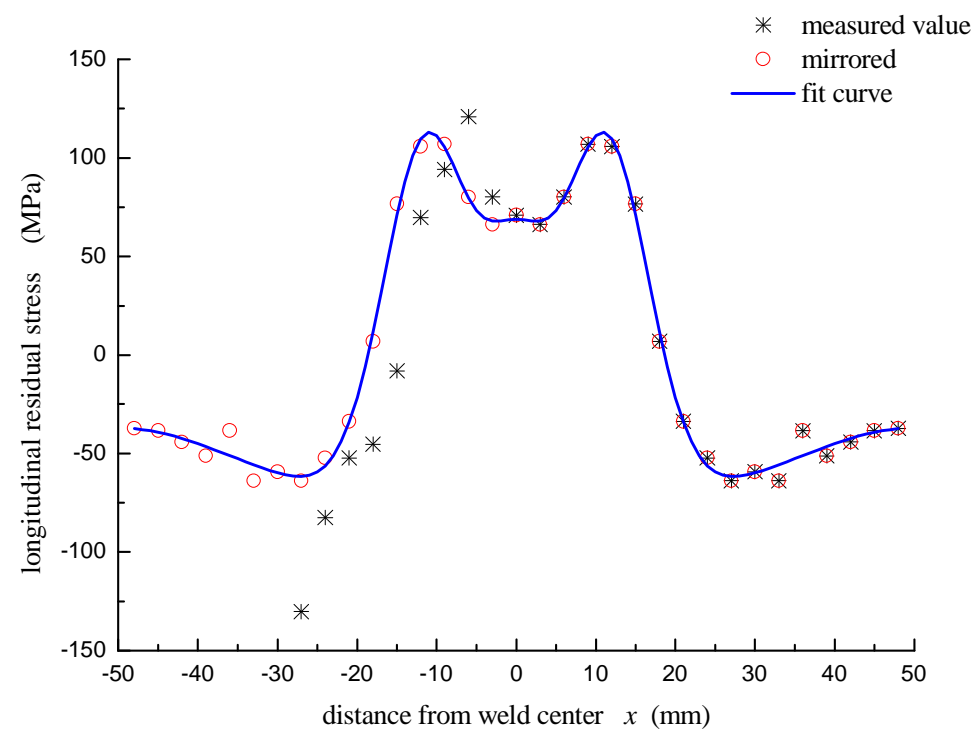

(a)

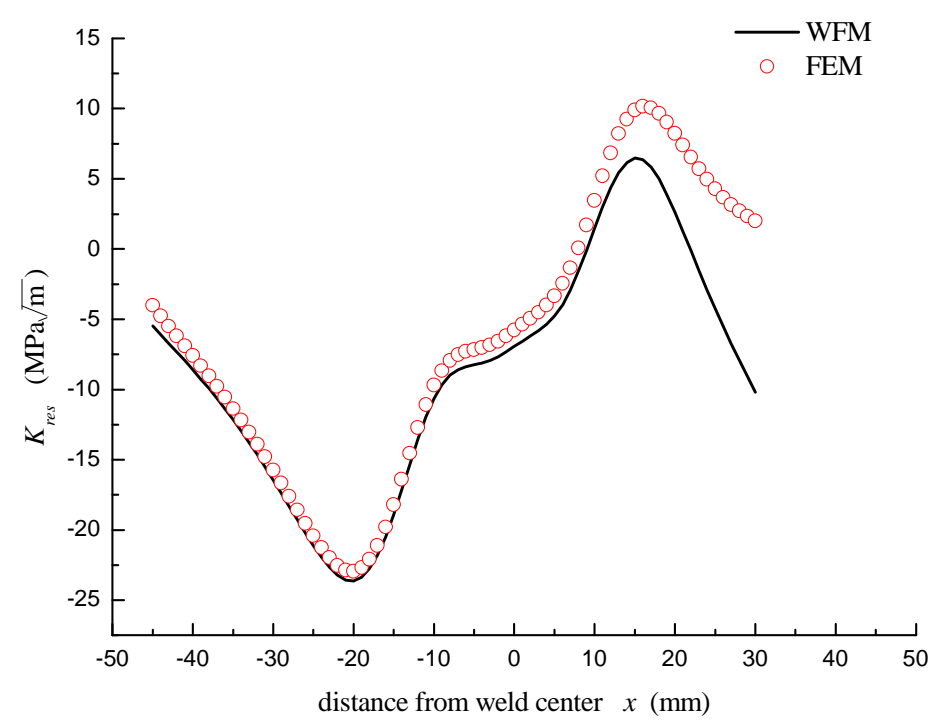

(b)

Fig. 15 (a) Residual stress redistributions; (b) calculated $K_{\text {res }}$ for the FSW 2195 ESE(T) specimen. 


\section{Conclusions and recommended calculation procedures}

An overview of the WFM and FEM procedures has been performed for evaluating residual stress intensity factors. According to the study described in this paper, especially on the treatment of un-balanced residual stresses, inputting residual stresses into FE models and SIF solution of negative residual stresses for the edge crack problem, following conclusions can be drawn:

1) For the $\mathrm{M}(\mathrm{T}), \mathrm{C}(\mathrm{T})$ and $\mathrm{ESE}(\mathrm{T})$ configurations presented in this paper, residual stress intensity factor solutions obtained by the WFM and FEM agree very well for $a / W<0.6$. For larger $a / W$ ratio, the difference between the two methods is caused by the inherent limitation of the WFM for longer crack lengths.

2) FE analysis procedures have been developed and validated by well-established weight functions; therefore, the FEM can be employed with confidence for longer crack lengths and for more complex geometries and structures.

3) Incomplete residual stress data have significant influence on the $K_{\text {res }}$ distribution evaluated by both the WFM and FEM when they are applied to a crack for which the residual stress is known only on a portion of the crack length (for instance an edge crack). If an incomplete measured stress distribution is artificially balanced, then the $K_{\text {res }}$ calculated by the FEM is acceptable in the region where the initial residual stresses are known from the measurement.

Following calculation procedures are recommenced for the FEM:

1) Measured residual stresses should be firstly processed, e.g. averaged, smoothed, fitted and mirrored, etc., before conducting FE analysis to obtain more accurate $K_{\text {res }}$ results. This is also recommended for the WFM solution process.

2) For incomplete or un-balanced residual stress data, adding artificial balancing stress will help to obtain acceptable $K_{\text {res }}$ values in the region where residual stresses are known.

3) In order to maintain self-equilibrium condition without any constraints and keep the model boundaries free of stresses, it is necessary to apply the "equilibrium" step in FE packages after inputting measured residual stresses.

4) For short-length geometries, higher (than the measured) residual stresses should be inputted into the FE model to accommodate the adjustment in the self-equilibrium step.

5) For cracks located in compressive residual stress field, external stress should be applied simultaneously to the residual stress field to make the crack surface completely open for calculating the total SIF. The residual SIF can then be found by the superposition principle.

\section{Acknowledgements}

$\mathrm{R}$ Bao is grateful to the China Scholarship Council for supporting her visit to the Cranfield University where this study was performed. N Ahmad Yahaya acknowledges the Malaysian Government for providing her a scholarship to study at Cranfield.

\section{APPENDIX}

1. $g_{i}(a / W)$ in Kaya and Erdogan weight function for single edge crack in a finite width plate, in Eq. (12) [23].

$$
g_{1}\left(\frac{a}{W}\right)=0.46+3.06\left(\frac{a}{W}\right)+0.84\left(1+\frac{a}{W}\right)^{5}+0.66\left(\frac{a}{W}\right)^{2}\left(1-\frac{a}{W}\right)^{2}
$$




$$
\begin{aligned}
& g_{2}\left(\frac{a}{W}\right)=-3.52\left(\frac{a}{W}\right)^{2} \\
& g_{3}\left(\frac{a}{W}\right)= 6.17-28.22\left(\frac{a}{W}\right)+34.54\left(\frac{a}{W}\right)^{2}-14.39\left(\frac{a}{W}\right)^{3}-\left(1-\frac{a}{W}\right)^{\frac{3}{2}} \\
&-5.88\left(1-\frac{a}{W}\right)^{5}-2.64\left(\frac{a}{W}\right)^{2}\left(1-\frac{a}{W}\right)^{2} \\
& g_{4}\left(\frac{a}{W}\right)=-6.63-25.16\left(\frac{a}{W}\right)-31.04\left(\frac{a}{W}\right)^{2}+14.41\left(\frac{a}{W}\right)^{3}+2\left(1-\frac{a}{W}\right)^{\frac{3}{2}} \\
&+5.04\left(1-\frac{a}{W}\right)^{5}+1.98\left(\frac{a}{W}\right)^{2}\left(1-\frac{a}{W}\right)^{2}
\end{aligned}
$$

2. Discrete value of coefficient $\beta_{i}(a / W)$ in $\mathrm{Wu}$ and Carlsson weight function for single edge crack in a finite width plate in Eq. (13) [17].

Table A1 $\beta_{i}(a / W)$ in Eq. (13)

\begin{tabular}{cccccc}
\hline$a / W$ & $\beta_{1}$ & $\beta_{2}$ & $\beta_{3}$ & $\beta_{4}$ & $\beta_{5}$ \\
\hline 0.01 & 2.00 & 0.9765 & 1.1420 & -0.3504 & -0.0912 \\
0.05 & 2.00 & 1.0927 & 1.1506 & -0.3662 & -0.0819 \\
0.10 & 2.00 & 1.4187 & 1.1378 & -0.3550 & -0.0763 \\
0.20 & 2.00 & 2.5366 & 1.2378 & -0.3474 & -0.0562 \\
0.30 & 2.00 & 4.2381 & 1.6796 & -0.4095 & -0.0188 \\
0.40 & 2.00 & 6.6359 & 2.8048 & -0.6105 & 0.0394 \\
0.50 & 2.00 & 10.0222 & 5.4999 & -1.3401 & 0.2178 \\
0.60 & 2.00 & 15.0359 & 11.8784 & -3.6067 & 0.7858 \\
0.70 & 2.00 & 29.5188 & 45.5066 & -18.9281 & 4.8834 \\
0.80 & 2.00 & 38.8128 & 78.7524 & -36.5957 & 9.8712 \\
0.85 & 2.00 & 53.8457 & 151.2119 & -79.0151 & 22.2696 \\
0.90 & 2.00 & 82.6869 & 350.9961 & -207.0916 & 60.8592 \\
\hline
\end{tabular}

3. Coefficient $A_{v, \mu}$ in Fett and Munz weight function for C(T) geometry in Eq. (14) [24]. Table A2 $A_{v, \mu}$ in Eq. (14)

\begin{tabular}{cccccc}
\hline$v$ & $\mu=0$ & 1 & 2 & 3 & 4 \\
\hline 0 & 2.673 & -8.604 & 20.621 & -14.635 & 0.477 \\
1 & -3.557 & 24.9726 & -53.398 & 50.707 & -11.837 \\
2 & 1.230 & -8.411 & 16.957 & -12.157 & -0.940 \\
3 & -0.157 & 0.954 & -1.284 & -0.393 & 1.655 \\
\hline
\end{tabular}

4. Discrete value of coefficient $\beta_{i}(a / W)$ in $\mathrm{Wu}$ and Carlsson weight function for $\mathrm{C}(\mathrm{T})$ geometry in Eq. (15) [17]. 
Table A3 $\beta_{i}(a / W)$ in Eq. (15)

\begin{tabular}{ccccc}
\hline$a / W$ & $\beta_{1}$ & $\beta_{2}$ & $\beta_{3}$ & $\beta_{4}$ \\
\hline 0.2 & 2.0 & 3.3270 & 1.4351 & -0.4652 \\
0.3 & 2.0 & 4.9886 & 1.7280 & -0.4130 \\
0.4 & 2.0 & 7.2610 & 2.7054 & -0.4570 \\
0.5 & 2.0 & 10.4356 & 5.2943 & -0.7632 \\
0.6 & 2.0 & 15.1033 & 11.3700 & -1.6671 \\
0.7 & 2.0 & 22.6843 & 26.0237 & -4.0924 \\
0.75 & 2.0 & 28.5976 & 41.2320 & -6.7399 \\
0.8 & 2.0 & 37.2393 & 69.1970 & -11.7568 \\
\hline
\end{tabular}

\section{References}

[1] Parker AP. Stress intensity factors, crack profiles, and fatigue crack growth rates in residual stress fields. Residual Stress Effects in Fatigue, ASTM STP 776, American Society for Testing and Materials, 1982; 13-31.

[2] Itoh YZ, Suruga S, Kashiwaya H. Prediction of fatigue crack growth rate in welding residual stress field. Eng Frac Mech 1989; 33: 397-407.

[3] Beghini M, Bertini L. Fatigue crack propagation through residual stress fields with closure phenomena. Eng Frac Mech 1990; 36: 379-387.

[4] Beghini M, Bertini L, Vitale E. Fatigue crack growth in residual stress fields: experimental results and modelling. Fatigue Fract Engng Mater Struct 1994; 17: 1433-1444.

[5] Pouget G, Reynolds AP. Residual stress and microstructure effects on fatigue crack growth in AA2025 friction stir welds. Int J Fatigue 2008; 30: 463-472.

[6] Fratini L, Pasta S, Reynolds AP, Fatigue crack growth in 2024-T351 friction stir welded joints: longitudinal residual stress and microstructural effects. Int J of Fatigue 2009; 31: 495-500.

[7] Elber W. The significance of fatigue crack closure. Damage Tolerance in Aircraft Structures. ASTM STP 486; American Society for Testing \& Materials; 1971. p. 230-42.

[8] Irving P E, Ma Y, Zhang X, Servetti G, Williams S, Moore G, et al.. Control of crack growth rates and crack trajectories in welded aircraft structures. Bridging the Gap between Theory and Operational Practice, Proceedings of ICAF 2009; 387-405.

[9] Glinka G, Shen G. Universal features of weight functions for cracks in mode I. Eng Frac Mech 1991; 40: $1135-46$.

[10] Servetti, G, Zhang, X. Predicting fatigue crack growth rate in a welded butt joint: the role of effective $R$ ratio in accounting for residual stress effect. Eng Frac Mech 2009; 76: 1589-1602.

[11] Labeas, G, Diamantakos, I. Numerical investigation of through crack behaviour under welding residual stresses. Eng Frac Mech 2009; 76: 1691-1702.

[12] Rooke DP, Baratta FI, Cartwright D J. Simple methods of determining stress intensity factors. Eng Frac Mech 1981; 14: 397-426.

[13] Sih GC, Paris PC, Erdogan F. Crack tip stress intensity factors for plane extension and plate bending problem. J App Mech, Trans ASME, 1962; 29:

[14] Gunguly S, Fitzpatrick ME, Edwards L, Use of neutron and synchrotron X-ray diffraction for evaluation of residual stresses in a 2024-T351 aluminium alloys variable-polarity plasma-arc weld. Metall Mater Trans A 2006; 37: 411-20.

[15] Prime MB. Residual stress measurement by successive extension of a slot: the crack compliance method. Appl Mech Rev 1999; 52: 75-96.

[16] Bao R, Zhang X. An inverse method for evaluating weld residual stresses via fatigue crack growth test data. Eng Frac Mech. (submitted) 
[17] Wu XR, Carlsson AJ. Weight Functions and Stress Intensity Factor Solutions. 1st ed. Oxford: Pergamon Press; 1991.

[18] Shah RC. Stress intensity factors for through and part-through cracks originating at fastener holes. Mechanics of crack growth, ASTM STP 590; American Society for Testing \& Materials; 1976. p. 429-59.

[19] Tada H, Paris P C, Irwin G R. The stress analysis of cracks handbook. 2nd ed. St. Louis Missouri: Paris Publications Incorporated; 1985.

[20] Sih G, Handbook of Stress Intensity Factors. Bethlehem Pennsylvania: Institute of Fracture and Solid Mechanics, Lehigh University; 1973.

[21] Isida M. Stress-Intensity factors for the tension of an eccentrically cracked strip. J App Mech 1966; 674-675.

[22] Bueckner HF. A novel principle for computation of stress intensity factors. Z. Angew Math Mech 1970; 529-546.

[23] Kaya AC, Erdogan F. Stress intensity factors and COD in an orthotropic strip. Int J Frac 1980; 16: 171-190.

[24] Fett T, Munz D, Stress Intensity Factors and Weight Functions. Southampton: Computational mechanics Publications; 1997.

[25] Petroski HJ, Achenbach JD. Computation of weight function from a stress intensity factor. Eng Frac Mech 1978; 10: 257-266.

[26] Beghini M, Bertini L, Di Lello R, Fontanari V. A general weight function for inclined cracks at sharp V-notches. Eng Frac Mech 2007; 74:602-611.

[27] Beghini M, Bertini L, Fontanari V. Stress intensity factors for an inclined edge crack in a semiplane. Eng Frac Mech 1999; 62:607-613.

[28] Fett T, Mattheck C, Munz D. Approximate weight function for 2D and 3D-problems. Engineering Analysis with Boundary Elements 1989; 6:48-63.

[29] Fett T, Mattheck C, Munz D. On the calculation of crack opening displacement from the stress intensity factor. Eng Frac Mech 1987; 27:697-715.

[30] Sha G T, Yang C T. Weight function of radial cracks emanating from a circular hole in a plate. Fracture Mechanics. ASTM STP 905; American Society for Testing \& Materials; 1986. p. 573600.

[31] Tada H, Paris PC, Irwin GR. The stress analysis of cracks handbook. 3rd ed. New York: The American Society of Mechanical Engineers; 2000.

[32] ABAQUS user/technical manual version 6.5. Hibbit, Karlsson and Sorensen Inc.;2005.

[33] Documentation for ANSYS Release 11.0. ANSYS Inc.; 2007.

[34] Lei Y, O'Dowd N P, Webster G A. Fracture mechanics analysis of a crack in a residual stress field. Int J Frac 2000; 106: 195-216.

[35] Anderson T L. Fracture Mechanics, Fundamentals and Applications. 3rd ed. Norway: CRC Press, Taylor and Francis Group; 2005.

[36] Ge YZ, Sutton MA, Deng X, Reynolds AP. Limited weld residual stress measurements in fatigue crack propagation: Part I Complete field representation through least-squares finiteelement smoothing. Fatigue Fract Engng Mater Struct 2006; 29: 524-536.

[37] Liljedahl CDM, Brouard J, Zanellato O, Lin J, Tan ML, Ganguly S, et al. Weld residual stress effects on fatigue crack growth behaviour of aluminium alloy 2024-T351. Int J Fatigue 2009; 31: 1081-1088. 